\title{
The expression of epidermal growth factor receptor and its downstream signaling molecules in osteosarcoma
}

\author{
SUNG-IM DO ${ }^{1}$, WOON WON JUNG ${ }^{2}$, HYUN SOOK KIM ${ }^{2}$ and YONG-KOO PARK ${ }^{1}$ \\ ${ }^{1}$ Department of Pathology, School of Medicine, Kyung-Hee University; \\ ${ }^{2}$ College of Health Sciences, Korea University, Seoul, Korea
}

Received July 24, 2008; Accepted October 27, 2008

DOI: 10.3892/ijo_00000205

\begin{abstract}
The value of epidermal growth factor receptor (EGFR) and its downstream signaling molecules as prognostic factors have been studied in many tumor types. The aim of this study was to investigate whether these molecules have prognostic value in osteosarcoma. We evaluated the immunostaining of EGFR and its downstream signaling molecules, p-EGFR, Akt, Stat-3, survivin and Erk in 47 osteosarcomas. In addition, three osteosarcoma cell lines were used to evaluate EGFR expression levels and mutation status by real-time PCR and nucleotide sequence analysis. Using tissue microarray of samples from 47 paraffinembedded osteosarcoma cases, 26, 17, 20 and 12 cases showed positive immunostaining of EGFR, Stat-3, survivin and Erk, respectively. Survivin and Erk were statistically correlated with survival $(\mathrm{p}=0.005$ and $\mathrm{p}=0.002$, respectively, log-rank test). Furthermore, we found that EGFR expression was correlated with Erk expression. In addition, we also observed a significant association of survivin expression with Stat- 3 and Erk activation $(p=0.006$ and $p=0.000$, Fisher's exact test). p-EGFR and Akt immunostaining were not detected in any of the cases. Two out of three osteosarcoma cell lines showed increased EGFR levels as detected by realtime PCR. One of these cell lines had a CAA to CAG mutation at exon 20 of the amplified EGFR gene, but this did not change the amino acid sequence. These results support the idea that Erk is a downstream signaling molecule of EGFR. Moreover, our data indicate that survivin and Erk could be used as prognostic factors in patients with osteosarcoma.
\end{abstract}

\section{Introduction}

The epidermal growth factor receptor (EGFR) is a member of the ErbB receptor tyrosine kinase family, which consists of

Correspondence to: Dr Yong-Koo Park, Department of Pathology, Kyung-Hee University College of Medicine, \#1, Heoigi-dong, Dongdaemun-gu, Seoul 130-702, Korea

E-mail: ykpark@khmc.or.kr

Key words: epidermal growth factor receptor, survivin, Erk, signal transducers and activators of transcription-3, osteosarcoma four transmembrane receptors: EGFR (ErbB1/HER1), ErbB2 (HER2/neu), ErbB3 (HER3) and ErbB4 (HER4). EGFR activation affects cell division, survival, invasion, adhesion, and angiogenesis and is a factor of poor prognosis (1-3). These effects are mediated by activation of downstream signal transduction cascades that include Janus tyrosine kinase (Jak)/signal transducers and activators of transcription (Stat), phosphatidylinositol 3 kinase (PI3K)/Akt and Ras/Raf/ mitogen-activated protein kinase (Erk) (4-6). In addition, survivin expression, which is downregulated by Stat, Akt, and Erk, is also a negative prognostic factor in some tumor types such as breast and lung cancer as well as head and neck cancer (7-9). Many studies have reported overexpression of EGFR in a number of common solid tumors, including non-small cell lung carcinoma, as well colon, breast, head and neck and ovarian cancers $(1,10)$. In addition, amplification of the EGFR gene and overexpression of the EGFR protein was observed in glioblastoma (11). Therefore, several EGFR-targeted therapies are used in the clinic, including the anti-EGFR monoclonal antibody cetuximab, tyrosine kinase inhibitors (TKIs), gefitinib and erlotinib (12-16). After binding to its ligand, EGFR undergoes autophosphorylation and transduces signals through several pathways that involve Stat, Akt, Erk and survivin.

After activation by the phosphotyrosine residues of EGFR, Stat modulates apoptosis, cell proliferation and differentiation (17-19). One of the members of the Stat family, Stat-3, is expressed in various human cancers such as lung, head and neck, breast cancer types (17,20-22).

Akt is also phosphorylated and activated by EGF through PI3-kinase. Activated Akt plays a role in various cellular processes such as glucose metabolism, DNA synthesis, cell cycle progression through anti-apoptotic signaling and cell survival $(23,24)$. In addition, hyperphosphorylation of Akt has been reported in many cases of non-small cell lung cancer (25).

Erk $1 / 2$ is activated by mitogenic agents and is a component of signal transduction cascades that regulate cell proliferation, survival and transformation (26-28). Activated Erk has been found in kidney, colon and lung cancers (27).

Survivin is a member of the inhibitor of apoptosis protein (IAP) family, which is present during fetal development but is not found in normal adult tissue $(29,30)$. The overexpression of survivin has been observed in many kinds of cancers including colorectal, breast, lung cancer and malignant 
lymphoma and has been suggested to be a negative prognostic factor (31-34).

Osteosarcoma is a primary high-grade malignant tumor in which the neoplastic cells produce osteoid. This disease is the most common, non-hematopoietic primary malignant tumor of the bone. Despite the fact that the relationship between EGFR and downstream molecules has been evaluated in many kinds of malignant tumors, no previous studies have simultaneously examined the status of EGFR and all four downstream molecules in osteosarcoma. The aim of this study was to analyze the expression and correlation of EGFR and its downstream signaling molecules to clinicopathological data in osteosarcomas.

\section{Materials and methods}

This study was approved by the IRB of Kyung-Hee University Hospital. Forty-seven formalin-fixed, paraffin-embedded osteosarcoma case samples, which had been sampled prior to chemotherapy, were obtained for this study. The samples were collected from 1983 to 2005 in the Department of Pathology at the Kyung-Hee University Hospital and the Hallym University Hospital. All cases were evaluated by two separate investigators (D.S.I. and P.Y.K.), using hematoxylin and eosin-stained sections. Hospital records were also reviewed for each case. A 0.3-mm tissue core was taken from each sample to include on tissue microarray slides. The cores were extracted from a representative part of the tumor according to the corresponding H\&E-stained slides. Immunohistochemical stains were performed on $4-\mu \mathrm{m}$ tissue sections cut from microarray paraffin blocks using an antibody against EGFR (EGFR, Clone 31G7, Zymed, CA, USA) 1:100 and four commercial antibodies from Cell Signaling Technology (MA, USA) against the phosphorylated forms of EGFR (pEGFR $^{\text {Tyr1068 }}$, polyclonal); 1:50, p-Stat3 ${ }^{\text {Tyr705 }}$ (monoclonal); 1:200, p-Akt ${ }^{\mathrm{Ser} 473}$ (monoclonal); 1:100, and p-Erk ${ }^{\mathrm{Tyr} 202 / \mathrm{Ty} 204}$ (monoclonal); 3:1000. In addition, a monoclonal antibody against survivin; 1:1000 (Neomarkers, Lab vision, CA, USA) was used. A bond-max immunohistochemistry auto-stainer (Vision Biosystem, VIC, Australia) was used for immunohistochemical staining. Placental tissue served as a positive control. Positive immunohistochemistry staining was evaluated by two investigators (D.S.I. and P.Y.K.) and positive expression was defined as $>10 \%$ of osteosarcoma cells with positive staining.

For real-time PCR and nucleotide sequencing, five cell lines (fibroblasts, ES97, MG63, SJSA-1 and HS3.7) were cultured in media (Gibco ${ }^{\mathrm{TM}}$, Invitrogen Corporation). Fibroblasts and ES97 (Ewing sarcoma) cells were used as controls, while MG63, SJSA-1 and HS3.7 served as the representative osteosarcoma cell lines in our study. RNA was isolated from cultured cells using an RNeasy kit (Qiagen). cDNA was synthesized from the RNA by using the $1^{\text {st }}$ strand cDNA kit (Roche, USA) (10X buffer $2.0 \mu 1,25 \mathrm{mM} \mathrm{MgCl}$ $4.0 \mu 1$, dNTP $2.0 \mu 1$, oligo-dT primer $2.0 \mu \mathrm{l}$, RNasin $1.0 \mu \mathrm{l}$, AMV reverse transcriptase $0.8 \mu 1$, RNA $1.0 \mu 1$ and sterile water) and a 9700 thermal cycler (ABI, Applied Biosystems, Foster City, USA). Real-time PCR was analyzed by using upl (Universal ProbeLibray Probes, cat, No. 04683633001 , Roche), [2X probe mixture; $10.0 \mu 1$, primer (10 pmol $/ \mu 1)$, upl
A

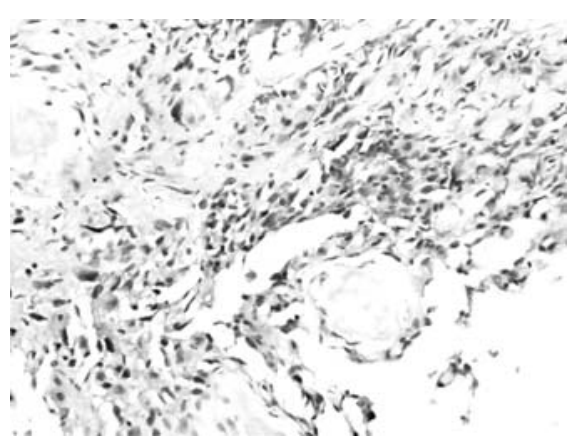

$\mathbf{B}$

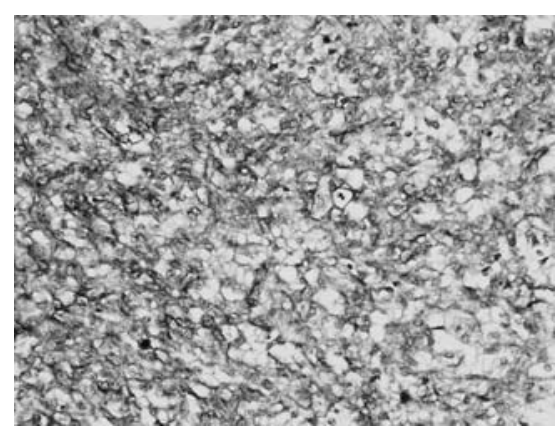

C



D

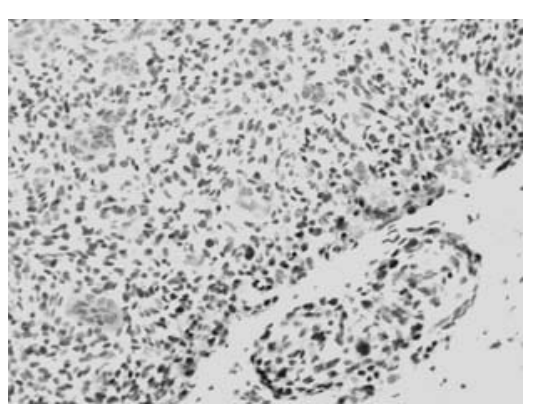

$\mathbf{E}$



Figure 1. Expression of EGFR and its downstream signaling molecules. Membranous staining of EGFR (A) and cytoplasmic staining of EGFR (B) are observed. Stat-3 (C) and Erk (D) show nuclear expression and survivin (E) shows cytoplasmic expression. 
Table I. The correlation between expression of each molecule (EGFR, Stat-3, Erk and survivin).

\begin{tabular}{|c|c|c|c|c|c|c|c|c|c|}
\hline & \multicolumn{3}{|c|}{ Stat-3 } & \multicolumn{3}{|c|}{ Erk } & \multicolumn{3}{|c|}{ Survivin } \\
\hline & $+(17)$ & $-(30)$ & P-value & $+(12)$ & $-(35)$ & P-value & $+(20)$ & $-(27)$ & P-value \\
\hline \multicolumn{10}{|l|}{ EGFR } \\
\hline$+(26)$ & 12 & 14 & & 10 & 16 & & 14 & 12 & \\
\hline$-(21)$ & 5 & 16 & & 2 & 19 & & 6 & 15 & \\
\hline & & & 0.138 & & & $0.042^{\mathrm{a}}$ & & & 0.137 \\
\hline \multicolumn{10}{|l|}{ Stat-3 } \\
\hline$+(17)$ & & & & 7 & 10 & & 12 & 5 & \\
\hline$-(30)$ & & & & 5 & 25 & & 8 & 22 & \\
\hline & & & & & & 0.087 & & & 0.006 \\
\hline \multicolumn{10}{|l|}{ Erk } \\
\hline$+(12)$ & & & & & & & 11 & 1 & \\
\hline$-(35)$ & & & & & & & 9 & 26 & \\
\hline
\end{tabular}

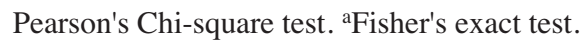

probe; $0.2 \mu \mathrm{l}$, DNA (100 ng/ $\mu \mathrm{l}) ; 2.0 \mu \mathrm{l}$ and sterile water] and the Light Cycler (Roche). For mutational analysis of the EGFR kinase domain, DNA was isolated from cultured cells using Magna Pure LC (Roche Diagnostics GmbH Mannheim, Germany) followed by PCR amplification using a 9700 thermal cycler (ABI, Applied Biosystems). After PCR fragment purification, a sequencing reaction (primer; $1.0 \mu \mathrm{l}$, BigDye terminator v.3.1; $8.0 \mu 1$, PCR fragments; $2.0 \mu 1$ and sterile water) and analysis (3100 genetic analyzer, ABI, Applied Biosystems) were performed.

Statistical analysis. Statistical analysis was carried out using SPSS software. A p-value $<0.05$ was considered statistically significant.

\section{Results}

In total, we analyzed 47 cases of osteosarcoma from patients ranging in age from 7 to 66 years, with a mean age of 25 years. Of these cases, 25 were male and 22 were female. The follow-up period ranged from 1 to 275 months and the mean follow-up time was 76.9 months. At the time of diagnosis, the 47 cases consisted of 20 stage I, 15 stage II, 7 stage III, and 1 stage IV tumors. In four cases, the stage had not been recorded in the hospital records. The femur was the most common tumor site (20 cases) followed by the humerus ( 5 cases), maxilla (4 cases), mandible ( 3 cases) and other sites. Of the tumors, 37 were osteoblastic, 5 were fibroblastic and 5 were chondroblastic types of osteosarcoma.

Twenty-six cases of osteosarcoma showed positive EGFR expression. Of these, 23 cases showed expression predominantly in the cytoplasm and 3 cases showed expression on the membrane surface (Fig. 1A and B). Nuclear expression of Stat-3, Erk, and cytoplasmic expression of survivin were observed in 17, 12 and 20 cases, respectively (Fig. 1C, D and E). Erk and survivin expression were statistically correlated with survival $(\mathrm{p}=0.005$ and $\mathrm{p}=0.002$, Kaplan-Meier test, Fig. 2C and D). In addition, we observed a correlation between EGFR and Erk expression ( $p=0.042$, Fisher's exact test). Moreover, we also observed a correlation between Stat-3 and survivin expression, as well as between Erk and survivin expression ( $\mathrm{p}=0.006$ and $\mathrm{p}=0.000$, Fisher's exact test) (Table I). However, EGFR and Stat-3 expression were not statistically correlated with survivin ( $\mathrm{p}=0.5319$ and $\mathrm{p}=0.1292$, Kaplan-Meier test, Fig. 2A and B). We did not observe p-EGFR and Akt expression in any of the cases. Moreover, no other correlations were found between the immunohistochemistry, staining of the molecules, and the other clinicopathological data, such as age, gender, or metastasis (Table II). In the real-time PCR results, increased EGFR and Akt levels were observed in two out of the three osteosarcoma cell lines, HS3.7 and MG63 (Fig. 3). In addition, the MG63 cell line showed increased Stat-3 levels. To investigate possible EGFR mutations, we sequenced the kinase domain from exons 18 to 21 in the cell lines. We found a point mutation which changed $A$ to $G$ at codon 54,031 at exon 20 (Fig. 4). However, this alteration in DNA sequence was silent i.e. it did not lead to a change in the amino acid (glutamine) at this position.

\section{Discussion}

Osteosarcoma is the most common primary malignant tumor of the bone and has an aggressive behavior. Previously, the long-term survival of patients has improved substantially as a result of neoadjuvant chemotherapy. However, despite these chemotherapy options, patients who have metastasis at the time of diagnosis or those with recurrent disease still show poor long-term survival (35). Thus a more advanced therapy for osteosarcoma is needed to achieve improved survival rates. For the same reason, previous studies have evaluated EGFR signaling and its downstream signaling molecules in many types of malignant tumors and have shown that these 
A

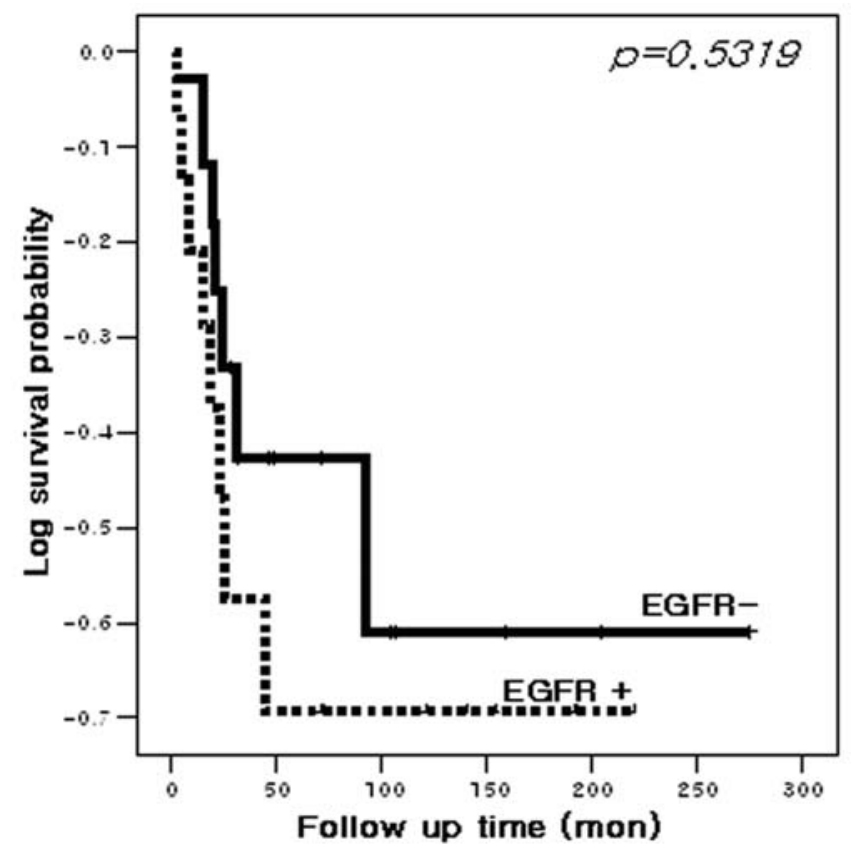

C

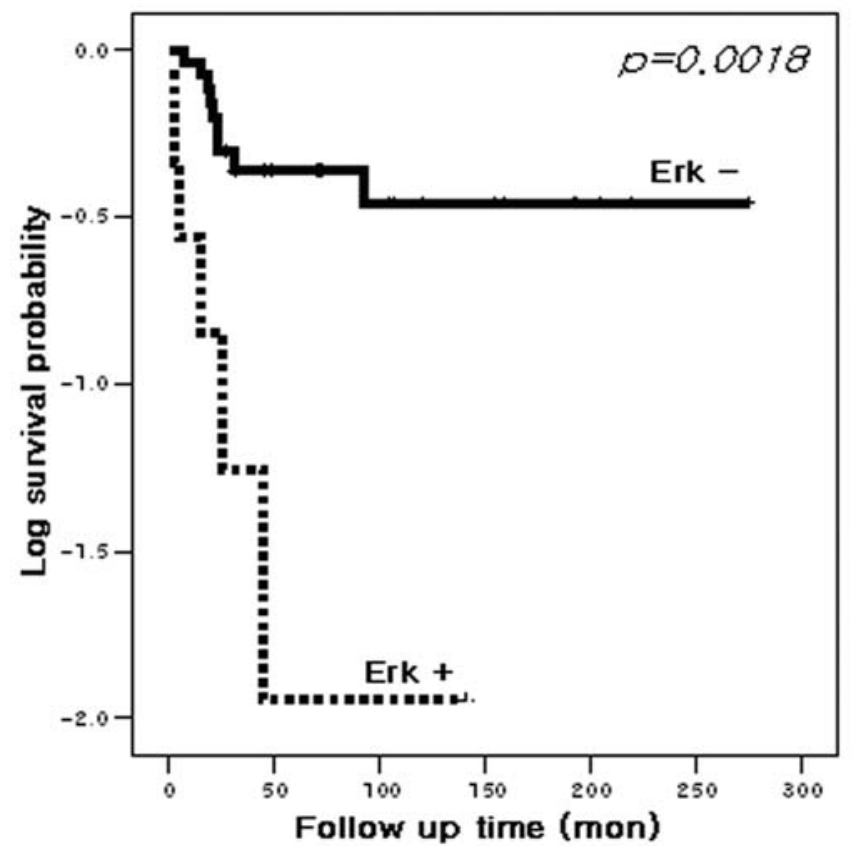

B

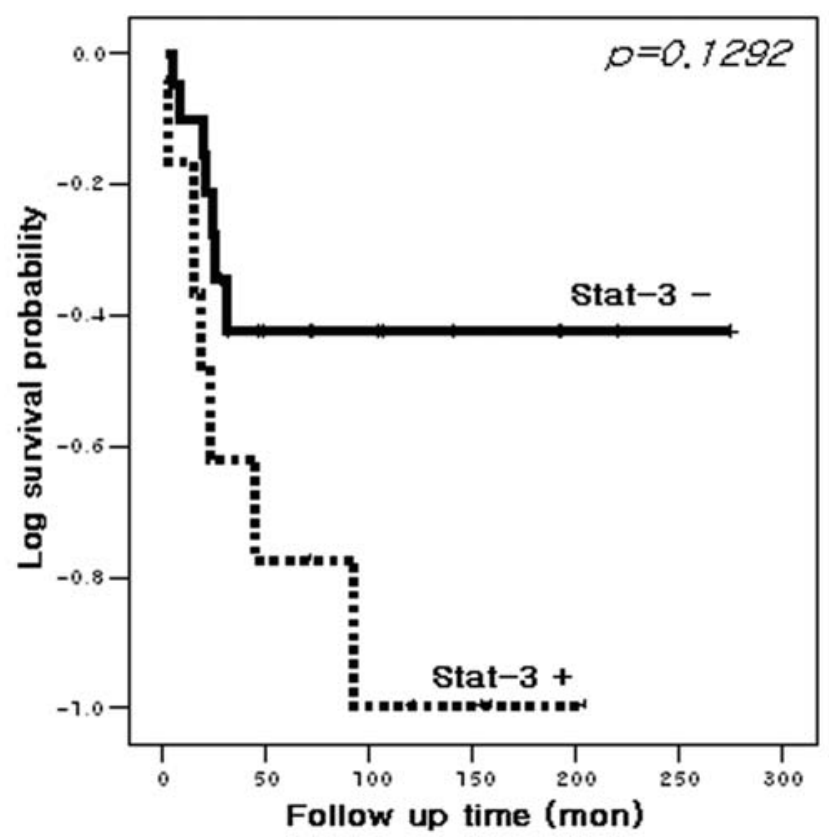

D

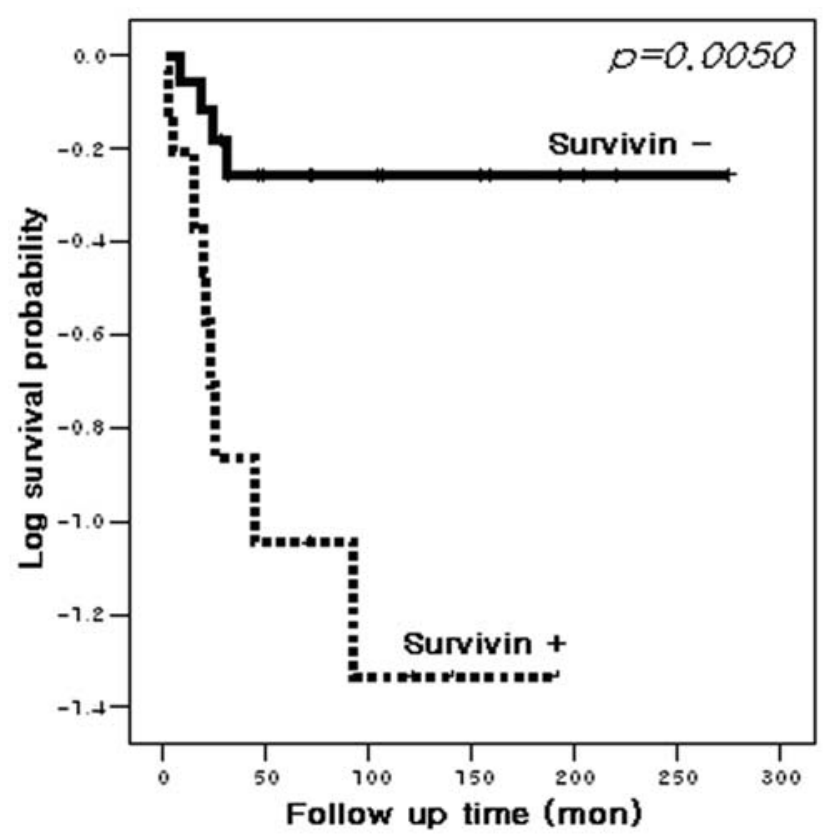

Figure 2. Survival analysis of EGFR and its downstream signaling molecules. EGFR (A) and Stat-3 (B) expression is not correlated with patient survival. However, expression of Erk (C) and survivin (D) shows a significant correlation with patient survival (Kaplan-Meier test, $\mathrm{p}=0.0018$ and 0.005 , respectively).

molecules can indicate poor prognosis (11-16). Moreover, only a few studies have focused on EGFR in osteosarcoma $(36,37)$. Nonetheless, no previous study has simultaneously examined EGFR and its four downstream signaling molecules in osteosarcoma. Our results showed positive EGFR expression in 26 cases $(55.3 \%)$, with cytoplasmic expression in 23 cases and membranous expression in 3 cases. Previous studies showed variable results with respect to the expression pattern of EGFR, ranging from $81 \%$ EGFR expression only in the cytoplasm of osteosarcoma to $57 \%$ of non-small cell lung cancer cases expressing membranous EGFR $(38,44)$. In our study, cytoplasmic and membrane expression of EGFR showed a statistical correlation with Erk expression. This result supports previous studies that have suggested that Erk is a downstream signaling molecule of EGFR $(1,2,5)$. Moreover, the possible role of EGFR should now be considered in osteosarcoma because real-time PCR showed an increased fold expression of EGFR in two of three osteosarcoma cell lines (HS3.7 and MG63). However, p-EGFR and Akt expression was not observed in any osteosarcoma case. In addition, placental tissue, which was used as a control tissue, also showed a negative result for Akt expression. We 
Table II. Clinicopathological data and expression of EGFR, Stat-3, Erk and survivin.

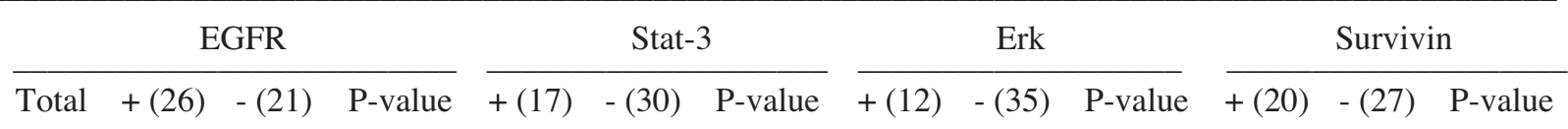

\begin{tabular}{|c|c|c|c|c|c|c|c|c|c|c|c|c|c|}
\hline \multicolumn{14}{|l|}{ Age } \\
\hline$\leq 25$ & 32 & 17 & 15 & 0.758 & 10 & 22 & 0.344 & 10 & 22 & $0.288^{a}$ & 15 & 17 & 0.529 \\
\hline$>25$ & 15 & 9 & 6 & & 7 & 8 & & 2 & 13 & & 5 & 10 & \\
\hline \multicolumn{14}{|l|}{ Gender } \\
\hline Male & 25 & 14 & 11 & 1.000 & 8 & 17 & 0.558 & 9 & 16 & $0.103^{\mathrm{a}}$ & 11 & 14 & 0.831 \\
\hline Female & 22 & 12 & 10 & & 9 & 13 & & 3 & 19 & & 9 & 13 & \\
\hline \multicolumn{14}{|c|}{ Metastasis } \\
\hline Present & 8 & 5 & 3 & $0.715^{\mathrm{a}}$ & 3 & 5 & $1.000^{\mathrm{a}}$ & 3 & 5 & $0.403^{\mathrm{a}}$ & 5 & 3 & $0.258^{\mathrm{a}}$ \\
\hline Absent & 39 & 21 & 18 & & 14 & 25 & & 9 & 30 & & 15 & 24 & \\
\hline
\end{tabular}

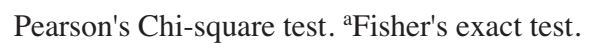



Figure 3. Real-time PCR result of EGFR. Increased EGFR level is observed in two out of the three osteosarcoma cell lines, HS3.7 and MG63.

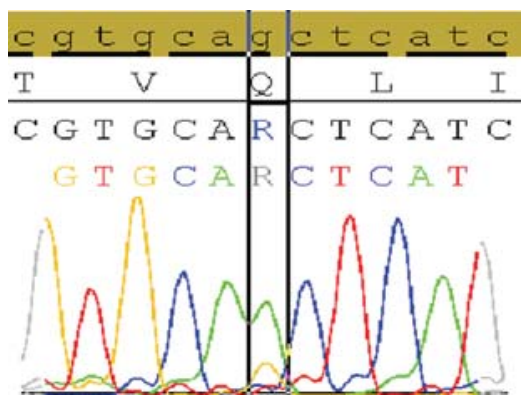

Figure 4. Mutation analysis of EGFR. the sequenced kinase domain from exons 18 to 21 in the cell lines show a point mutation which changed A to G at codon 54,031 at exon 20. However, it did not lead to a change in the amino acid (glutamine) at this position. used various staining protocols and repeated our immunohistochemical staining of p-EGFR and Akt; however, the staining results were not significantly different from one another. In real-time PCR, the two cell lines which showed increased EGFR expression also showed increased Akt expression. Although the number of cell lines in our study was small, a relationship between EGFR and Akt appears to exist. In our study, Erk and survivin expression were statistically correlated with survival of patients and this finding is consistent with previous studies that have suggested that these molecules are prognostic factors that indicate a poor prognosis (26-28,31-34). In particular, survivin expression was correlated with Erk and Stat-3 expression and this supports the idea that 
survivin is a downstream signaling molecule of Erk and Stat-3 $(7,8,39)$. One study suggested that survivin is regulated via Erk through the PI3K signaling pathway. The authors of this study observed decreased survivin expression after using an Erk inhibitor (40). Furthermore, another study showed inhibition of survivin expression by using a drug that downregulates the Stat-3 signaling pathway in head and neck cancer (7). Therefore, Erk inhibiting or Stat-3 inhibiting drugs in osteosarcoma patients could potentially considerably increase patient survival rate. Our results showed Stat-3 expression in 17 cases of osteosarcoma, but we found no statistical correlation between EGFR expression and the clinicopathological data. One previous study has shown Stat-3 activation in bone and soft tissue tumors, but these studies did not find Stat-3 expression in the three osteosarcoma cases included (41).

The discrepancy between EGFR and Stat-3 expression may be as a result of the following. First, EGFR activation is not an essential step for Stat-3 signal transduction in osteosarcoma. In addition, some studies have described EGFR-independent activation of Stat-3 in vivo and in vitro $(18,19)$. Second, other EGFR transduction pathways such as PI3K or the Ras/Raf/ mitogen-activated protein kinase pathway possibly could be activated instead of the JAK/STAT signaling pathway. In fact, our results showed a statistical correlation between EGFR and Erk expression. However, the indirect effect of Stat-3 on patients via an increased expression of survivin should be considered.

We found one point mutation (A to $\mathrm{G}$ ) at codon 54031 in exon 20 of the EGFR gene that did not lead to a change in the amino acid sequence. Previous studies of EGFR gene mutations in osteosarcoma found a point mutation at codon 863 in exon 21, E829E and R831C in exon $21(36,41)$. Of all of these mutations, only one mutation (R831C in exon 21) resulted in an amino acid change from arginine to cysteine. Accordingly, the type and location of mutations may have different spectrums in osteosarcoma. Previously, EGFR targeted therapies, as well as tyrosine kinase inhibitors, have been clinically used to treat many kinds of cancers $(42,43)$. In addition, non-small cell lung carcinoma patients with EGFR mutations present in the cancer show a favorable clinical prognosis that is associated with an increased sensitivity to tyrosine kinase inhibitors (44-46). Considering the presence of EGFR mutations and the positive expression of EGFR, osteosarcomas may also be sensitive to tyrosine kinase inhibitors.

In conclusion, expression of Erk and survivin in osteosarcoma may indicate an unfavorable patient prognosis and an EGFR mutation may be a variable event in osteosarcoma. Moreover, trials of Erk- or Stat-3-inhibiting drugs should be considered in osteosarcoma patients with survivin expression. Nevertheless, a large-scale EGFR mutation evaluation in osteosarcomas is needed to determine their potential sensitivity to molecular targeting therapies.

\section{Acknowledgements}

This study was supported by the Kyung-Hee University Research Fund in 2007 (KHU-20071608). A part of the data was presented in USCAP in 2007.

\section{References}

1. Yarden Y and Sliwkowski MX: Untangling the ErbB signalling network. Nat Rev 2: 127-137, 2001

2. Jorissen RN, Walker F, Pouliot N, Garrett TP, Ward CW and Burgess AW: Epidermal growth factor receptor: mechanisms of activation and signalling. Exp Cell Res 284: 31-53, 2003.

3. Mendelsohn J and Baselga J: Status of epidermal growth factor receptor antagonists in the biology and treatment of cancer. J Clin Oncol 21: 2787-2799, 2003

4. Calo V, Migliavacca M, Bazan V, et al: STAT proteins: from normal control of cellular events to tumorigenesis. J Cell Physiol 197: 157-168, 2003.

5. Weinstein-Oppenheimer CR, Blalock WL, Steelman LS, Chang F and McCubrey JA: The Raf signal transduction cascade as a target for chemotherapeutic intervention in growth factor-responsive tumors. Pharmacol Ther 88: 229-279, 2000.

6. Vivanco I and Sawyers CL: The phosphatidylinositol 3-Kinase AKT pathway in human cancer. Nat Rev Cancer 2: 489-501, 2002.

7. Scheper MA, Nikitakis NG and Sauk JJ: Survivin is a downstream target and effector of sulindac-sensitive oncogenic Stat3 signalling in head and neck cancer. Int J Oral Maxillofac Surg 36: 632-639, 2007.

8. Kumar P, Coltas IK, Kumar B, Chepeha DB, Bradford CR and Polverini PJ: Bcl-2 protects endothelial cells against gammaradiation via a Raf-MEK-ERK-survivin signaling pathway that is independent of cytochrome c release. Cancer Res 67: 1193-1202, 2007.

9. Asanuma H, Torigoe T, Kamiguchi K, et al: Survivin expression is regulated by coexpression of human epidermal growth factor receptor 2 and epidermal growth factor receptor via phosphatidylinositol 3-kinase/AKT signaling pathway in breast cancer cells. Cancer Res 65: 11018-11025, 2005.

10. Hynes NE and Lane HA: ERBB receptors and cancer: the complexity of targeted inhibitors. Nat Rev Cancer 5: 341-354, 2005.

11. Smith JS, Tachibana I, Passe SM, et al: PTEN mutation, EGFR amplification, and outcome in patients with anaplastic astrocytoma and glioblastoma multiforme. J Natl Cancer Inst 93: 1246-1256, 2001.

12. Baselga J: Targeting tyrosine kinases in cancer: the second wave. Science 312: 1175-1178, 2006.

13. Pao W and Miller VA: Epidermal growth factor receptor mutations, small-molecule kinase inhibitors, and non-small-cell lung cancer: current knowledge and future directions. J Clin Oncol 23: 2556-2568, 2005.

14. Moroni M, Veronese S, Benvenuti S, et al: Gene copy number for epidermal growth factor receptor (EGFR) and clinical response to antiEGFR treatment in colorectal cancer: a cohort study. Lancet Oncol 6: 279-286, 2005.

15. Lee JW, Soung YH, Kim SY, et al: Somatic mutations of EGFR gene in squamous cell carcinoma of the head and neck. Clin Cancer Res 11: 2879-2882, 2005.

16. Bunn PA Jr and Franklin W: Epidermal growth factor receptor expression, signal pathway, and inhibitors in non-small cell lung cancer. Semin Oncol 29: 38-44, 2002.

17. Song L, Turkson J, Karras JG, Jove R and Haura EB: Activation of Stat3 by receptor tyrosine kinases and cytokines regulates survival in human non-small cell carcinoma cells. Oncogene 22: 4150-4165, 2003.

18. Bowman T, Garcia R, Turkson J and Jove R: STATs in oncogenesis. Oncogene 19: 2474-2488, 2000.

19. Levy DE and Darnell JE Jr: Stats: transcriptional control and biological impact. Nat Rev 3: 651-662, 2002.

20. Grandis JR, Drenning SD, Zeng Q, et al: Constitutive activation of Stat3 signaling abrogates apoptosis in squamous cell carcinogenesis in vivo. Proc Natl Acad Sci USA 97: 4227-4232, 2000.

21. Garcia R and Jove R: Activation of STAT transcription factors in oncogenic tyrosine kinase signaling. J Biomed Sci 5: 79-85, 1998.

22. Lai R, Navid F, Rodriguez-Galindo C, et al: STAT3 is activated in a subset of the Ewing sarcoma family of tumours. J Pathol 208: 624-632, 2006.

23. Brognard J, Clark AS, Ni Y and Dennis PA: Akt/protein kinase B is constitutively active in non-small cell lung cancer cells and promotes cellular survival and resistance to chemotherapy and radiation. Cancer Res 61: 3986-3997, 2001.

24. Sakoda H, Gotoh Y, Katagiri H, et al: Differing roles of Akt and serum- and glucocorticoid-regulated kinase in glucose metabolism, DNA synthesis, and oncogenic activity. J Biol Chem 278: 25802-25807, 2003. 
25. Shah A, Swain WA, Richardson D, et al: Phospho-akt expression is associated with a favorable outcome in non-small cell lung cancer. Clin Cancer Res 11: 2930-2936, 2005.

26. Lin AW, Barradas M, Stone JC, van Aelst L, Serrano M and Lowe SW: Premature senescence involving p53 and p16 is activated in response to constitutive MEK/MAPK mitogenic signaling. Genes Dev 12: 3008-3019, 1998.

27. Hoshino R, Chatani Y, Yamori T, et al: Constitutive activation of the 41-/43-kDa mitogen-activated protein kinase signaling pathway in human tumors. Oncogene 18: 813-822, 1999.

28. Cappuzzo F, Magrini E, Ceresoli GL, et al: Akt phosphorylation and gefitinib efficacy in patients with advanced non-small-cell lung cancer. J Natl Cancer Inst 96: 1133-1141, 2004.

29. Hirohashi Y, Torigoe T, Maeda A, et al: An HLA-A24-restricted cytotoxic T lymphocyte epitope of a tumor-associated protein survivin. Clin Cancer Res 8: 1731-1739, 2002.

30. Ambrosini G, Adida C, Sirugo G and Altieri DC: Induction of apoptosis and inhibition of cell proliferation by survivin gene targeting. J Biol Chem 273: 11177-11182, 1998.

31. Kawasaki H, Altieri DC, Lu CD, Toyoda M, Tenjo T and Tanigawa N: Inhibition of apoptosis by survivin predicts shorter survival rates in colorectal cancer. Cancer Res 58: 5071-5074, 1998.

32. Monzo M, Rosell R, Felip E, et al: A novel anti-apoptosis gene: Re-expression of survivin messenger RNA as a prognosis marker in non-small-cell lung cancers. J Clin Oncol 17: 2100-2104, 1999.

33. Kennedy SM, O'Driscoll L, Purcell R, et al: Prognostic importance of survivin in breast cancer. Br J Cancer 88: 1077-1083, 2003.

34. Adida C, Haioun C, Gaulard P, et al: Prognostic significance of survivin expression in diffuse large B-cell lymphomas. Blood 96: 1921-1925, 2000.

35. Nagarajan R, Clohisy D and Weigel B: New paradigms for therapy for osteosarcoma. Curr Oncol Rep 7: 410-414, 2005.

36. Wen YH, Koeppen H, Garcia R, et al: Epidermal growth factor receptor in osteosarcoma: expression and mutational analysis. Hum Pathol 38: 1184-1191, 2007.

37. Hughes DP, Thomas DG, Giordano TJ, Baker LH and McDonagh KT: Cell surface expression of epidermal growth factor receptor and Her-2 with nuclear expression of Her-4 in primary osteosarcoma. Cancer Res 64: 2047-2053, 2004.
38. Oda Y, Wehrmann B, Radig K, et al: Expression of growth factors and their receptors in human osteosarcomas. Immunohistochemical detection of epidermal growth factor, platelet-derived growth factor and their receptors: its correlation with proliferating activities and p53 expression. Gen Diagn Pathol 141: 97-103, 1995.

39. Jalal Hosseinimehr S, Inanami O, Hamasu T, et al: Activation of c-kit by stem cell factor induces radioresistance to apoptosis through ERK-dependent expression of survivin in HL60 cells. J Radiat Res 45: 557-561, 2004.

40. Siddiqa A, Long LM, Li L, Marciniak RA and Kazhdan I: Expression of HER-2 in MCF-7 breast cancer cells modulates anti-apoptotic proteins Survivin and Bcl-2 via the extracellular signal-related kinase (ERK) and phosphoinositide-3 kinase (PI3K) signalling pathways. BMC Cancer 8: 129, 2008.

41. Dobashi Y, Suzuki S, Sugawara H and Ooi A: Involvement of epidermal growth factor receptor and downstream molecules in bone and soft tissue tumors. Hum Pathol 38: 914-925, 2007.

42. Hidalgo M, Siu LL, Nemunaitis J, et al: Phase I and pharmacologic study of OSI-774, an epidermal growth factor receptor tyrosine kinase inhibitor, in patients with advanced solid malignancies. J Clin Oncol 19: 3267-3279, 2001.

43. Wakeling AE, Guy SP, Woodburn JR, et al: ZD1839 (Iressa): an orally active inhibitor of epidermal growth factor signaling with potential for cancer therapy. Cancer Res 62: 5749-5754, 2002.

44. Cappuzzo F, Hirsch FR, Rossi E, et al: Epidermal growth factor receptor gene and protein and gefitinib sensitivity in non-smallcell lung cancer. J Natl Cancer Inst 97: 643-655, 2005.

45. Lynch TJ, Bell DW, Sordella R, et al: Activating mutations in the epidermal growth factor receptor underlying responsiveness of non-small-cell lung cancer to gefitinib. N Engl J Med 350: 2129-2139, 2004.

46. Paez JG, Janne PA, Lee JC, et al: EGFR mutations in lung cancer: correlation with clinical response to gefitinib therapy. Science 304: 1497-1500, 2004. 